\title{
Comparing the Teaching Assessment Modes of China and Britain
}

\author{
TING XUE \\ University of Wolverhampton \\ WV1 1LY \\ United Kingdom \\ $\&$ \\ Northeast Normal University \\ 130056 \\ China
}

\begin{abstract}
On the basis of the research work dealing with the current scenario of the teaching evaluation at home and abroad, the current paper carries out the comparison of the summative classroom assessment with the formative classroom assessment in China and Britain, together with pointing out flaws in the summative classroom assessment as a teaching test and incentive mechanism, and introducing the popularization significance of the formative classroom assessment, which aim at throwing discussion on the significance of developing the formative classroom assessment in a Chinese teaching classroom.
\end{abstract}

Keywords: formative assessment, summative assessment, comparison

\section{Introduction}

Assessment plays a pivotal role in teaching and learning both. It is employed in classrooms for the purpose of helping students learn well. In the education system, assessment is defined as: Educators make use of various methodologies or tools for assessing and recording the students' academic readiness, learning progress, skills acquisition, or educational needs (Harlen, 1994). For me, there is a more suitable definition, which suggests that he assessment is best described as a process, wherein teachers make use of the assessment information for the adjustment of their teaching strategies and students adjust their learning strategies (Marsh, 2009).

Assessments are also designed in various means for purposes. In the year 2001, the NRC explicated that the Education assessment is designed for the determination of the quality of students' learning, besides being a pivotal component of looking for the improvement in education. It provides feedback for not only students, but also educators, parents, policy makers and the public institutions. To summarize, assessments are typically created for highly specialized purposes. The assessment primarily aims at improving the students' learning ability as well as the teacher's teaching (Gardner, 2012). They can both respond to the information it provides. Moreover, using the assessment has an incentive impact on the students 'learning. Accordingly, the assessment impacts the students' motivation. The type of assessment directly impacts the students 'learning style as well as learning content. In a case where I analyze the assessment individually, it will be divided into three aspects. With regard to the teachers, assessment helps them attain information in order to plan and revise teaching and learning plans for each student, group students, and even entire classes. It is expected to help figure out the advantages of students so that teachers and students could depend on the information they obtain (Garman, 2017). Besides that, it benefits teachers to figure out students' learning demands in a clear and effective manner for the solution of issues. Subsequent to the assessment, students' parents could have a better means of participating in the children's learning. With regard to students, the assessment is expected to provide them with some information, together with leading them to carry out a plan for the next steps in their learning. Moreover, with regard to school leaders, they can make use of the information for the school-wide planning, to support their teachers and figure out the professional development demands. While assessment is likely to assume an extensive variety of forms in education, for instance, the highstakes assessment, pre-assessment, formative assessment, summative assessment, interim assessment, placement assessment and screening assessment (Wiliam, 2017), I am going to will choose the formative assessment and summative assessment methodologies for the introduction in this article since they are new assessment forms for me. 
Moreover, because I have come to the UK, I have suffered an extensively different assessment approach with China, and I am interested in throwing discussion on differences and carrying out some comparisons in my perspective.

\section{Literature Review}

Black and Wiliam (1998) suggest that the formative assessment tells teachers where the students are and what the next step is, which is typically not scored or graded. It is meant for providing the feedback for educators, and teachers can incorporate some modifications into teaching methodologies and some other factors. Nonetheless, the summative assessment is employed for the evaluation of students' learning outcomes, typically at the end of a course or semester. It is expected to have scores or grades. Black (2003) puts forward that the formative assessment is typically called for learning as educators make use of results in order to modify and enhance the teaching mechanism and skills; moreover, the summative assessment is associated with the learning since the academic achievements in a teaching period conclusion are evaluated. If we are interested in having a better understanding of the assessment, we require finding out the original theories, together with analyzing the learning experiences by means of the same.

The theory of behaviorism in the era of 1930s was most closely associated with the work of Pavlov, James Watson, B.F. Skinner, and Thank. Behaviourismplaced emphasis on a dominant theoretical perspective that teachers require being trained, and they could still be viewed in the behavioral process as well as everyday practice. Since the environment is termed as a pivotal factor impacting the people, the learning could be treated as an external stimulus (Bredo, 1997). Rewards and punishments can be reinforcements for students, as well. Accordingly, the assessment is the achievement in learning; it is the result of learning. The significance of the assessment suggests that the progress is measured with the use of tests. Performance is usually interpreted as correct or incorrect, and poor performance can be compensated by means of more practice on incorrect items, at times, through the further deconstruction of them, together with returning to more basic skills. Following the behaviorism, there are several theories, for instance, cognitivism, constructivism, and social constructivism.

The previous learning has the potential to impact the later learning, and the formative assessment constitutes a pivotal component of the teaching practice since it is essential to lead to students' mental models (through classroom conversations, open tasks, loud thinking protocols, and concept maps) for supporting their understanding regarding the structure of knowledge and providing them with opportunities to apply concepts and strategies in new situations (Bruner, 1996).

Considering the perspective of a social construct on learning, the assessment plays a crucial role. The learning has taken place in the interaction between the pupils and the environment (Vygotsky, 1978). Increasing numbers of teachers develop the understanding of the "scaffold," who are helpers for students, not deciders and leaders. Assessments have the same position; irrespective of what assessment they apply, they all undergo the second place. Students make use of collaboration with teachers, students and tools for the development of their knowledge maps.

Together with learning theories, political, economic and cultural factors also impact the education and assessment, together with making it do some changes in accordance with them. Education has a close association with the politics, economy and culture (MacDermott, 2013). They not only promote but also restrict each other. In China, politics has been leading the development of education. The nature of politics is capable of determining the content and methodologies of education. Unquestionably, the assessment is also included in the education system. For instance, almost ten years ago, China launched a policy of sunshine sports, aimed at promoting sports and helping the Chinese youngsters develop the habit of sports and build healthy bodies. Thereafter, this policy is carried out in various high schools and universities. Aimed at attaining good results, the physical education is also added to the examination evaluation of the high school for entering the university, making the physical quality one of the students' standards (Dann, 2014). This measure helps students develop good exercise habits, in addition to making China's education system more comprehensive and complete.

In addition, the economic progress is also expected to push forward the progress of education. If the economy develops to a specific level, the education will be fully developed (Gratton-Lavoie and Stanley, 2009). In the due course of education, the establishment of educational facilities, the cost of education and training, all ask for the economic assistance. The hardware facilities of the school constitute a prerequisite for the software facilities. 
It also constitutes a key link in the theory of Bronfenbrenner ecological system, which has the potential to help students have a good system environment, together with getting a better education (Bronfenbrenner, 1994). The economy is termed as a pivotal condition for the development of education. The reform of the economic system is capable of bringing about the introduction of education, and the change in the old economic system has the potential to make the development of education space (Berkhout, Hertin and Jordan, 2002).

Politics, economy, and culture belong to the fourth environmental systems of Bronfenbrenner ecological system, the macro system. The macro system is a broad ideology, which specifies how to treat students, teaching students what they should strive for. These ideas are different in different cultures, meanwhile still existing in the micro system, the middle system and the external system, directly or indirectly impacting the acquisition of the students' knowledge and experience.

\section{Strength of Formative Assessment}

Meyers and Nulty (2009) put forward that the formative assessment process stems from educators, committed to accelerating the student achievement and helping predict how students are going to be tested.

The benefits associated with formative assessment are evident in the classroom. The use of the formative assessment in the classroom works a guide to teach, and the approach in which students are mastered provides several advantages, far exceedingly higher test scores. In accordance with Rowntree (2010), despite the fact that all formative assessment practices are likely to enhance the students' learning potential, there are some of the evident benefits of the formative assessment, presented as hereunder.

The time-saving of the results makes the teachers capable of quickly changing their teaching during the process of learning. The students being assessed are the students benefitting from adjustments. Students have the option to use these data for changing and improving their learning. As for my experience is concerned, it is the best means of fitting my mistakes and having a clear thought to do the next step.

With the help of the formative assessment, teachers work with students, and they do not do everything for students (German, 2017). They try using the formative assessment data for the purpose of helping students master the curriculum and figure out their strengths and weaknesses. In the last semester, there is an actually important and difficult module which is called research methods; it is a starting course for postgraduate students, and I require having my proposal to the final research. Nonetheless, it is unfamiliar to me to the proposal, so I did not do very well; thanks to the formative assessment, which provided me with an opportunity to have a tutorial with my course leader, and the talking really helped me a lot. In accordance with my work, the teacher gives me with the feedback that includes the good points I write, the improvement I need to do, and the mistakes I should change. It is an enjoyable process for me, together with significantly inspiring me.

The formative assessment also helps students define learning goals. The regular monitoring of students' learning progress helps prioritize the learning goals so that they could have clear work goals and teachers could help do away with the confusions before the students leave the pace (Roskos and Neuman, 2012). Once teachers understand why students require succeeding, they can develop a convenient learning environment, which challenges each student's growth. In the formative assessment, both teachers and students themselves are capable of providing timely feedback for the students themselves from their usual performance, so that they could understand their progress as well as issues in learning. Students have changed from passive evaluators to the key body of the supervisory evaluation system. They have started understanding that evaluation is not a goal. It is the means. It is a productive means for them to understand their own learning. When students develop a good understanding of what they want to learn, together with what they should learn, they are expected to develop an interest. Moreover, the formative assessment and summative assessment can also enhance the students' academic output. They can also provide students and teachers with the normal feedback on the progress. And, the achievement of goals is the key function of the formative assessment, which helps improve academic output. Moreover, the formative assessment helps students bridge the difference between their current knowledge and their learning goals. The summative assessment helps students accomplish their goals, in addition to getting final scores.

Both the formative and summative assessments release pressure for students. Moreover, the formative assessment is likely to lower the test anxiety that students typically encounter at the end of the course. They are likely to have trouble performing well under pressure. If they could get proper training, teachers can make use of these assessments for the purpose of guiding the eventual mastery. 
Nonetheless, as teachers, they require mandatorily being careful not to spend all of their time performing formative assessments; they also require accomplishing the course first. Accordingly, using the formative assessment is dependent on the teacher's familiarity with the subject's knowledge of the student.

The formative assessment is not graded, which is not expected to make students feel anxious. It also strips them of the idea that they must get things done. Rather than that, they can be employed as exercises for students for getting help prior to the final testing. If students are struggling in class, the teacher is expected to check if they understand the same (McLachlan, 2006). Teachers have the ability to solve these issues at the earliest possible, rather than waiting until the unit evaluation is over. The teacher is required to re-learn in the end because several mastery issues are solved prior to the final test.

The formative assessment and summative assessment are counted among the most popular assessment forms in the progressive education. If the leaders are able to employ them effectively, it will lead to a significant result.

\section{Limitations of Summative Assessment}

Unquestionably, with various advantages, there are still several disadvantages when both the formative assessment and summative assessment are taken into consideration (Clark, 2012). The most significant point I encountered is the time-consumption. In China, teachers are not expected to make use of lessons for assessing the students' learning outcomes; they consider it as a sacrifice for the time, and they fear that they are unable to accomplish the lesson. Thereafter, they find it quite essential to catch the course by means of a series of units. Once the unit is evaluated at the end of the unit, it is going to result into a lack of mastery. Kickert, et al (2018) put forward that teachers also require spending time analyzing the results and providing each student with the detailed feedback (perhaps 50 students per class in China). Accordingly, realistically speaking, teachers require spending too much time to continue, accurately and completely doing this. Chinese teachers are likely to be short of training or professional development on how to employ the formative assessments successfully. Owing to the fact that, historically, the assessment was finalized, at times, the formative assessment is not graded so that the students may not take the formative assessment seriously, which is likely to give rise to the teachers' misreading of the student feedback. Nevertheless, as it is done and done effectively, it is one of the most powerful and influential means of improving the learning process.

Comprehensively speaking, I stated in the last paragraph that teachers require providing every student with the feedback; this process of planning and exercising can be exhausting for teachers, and some of them might not be capable of adhering to complete at all years. Accordingly, this disadvantage is likely to lead many educators to avoid this assessment as well as practice. A complex progress makes it quite tough to finish (Watts and Hodgson, 2015).

From three modules I learned, I realized the fact that the feedback in the formative assessment has a high demand for professors. They require having a clear thought regarding learners' research topics, together with providing them with targeted opinions. Subsequent to the collection of the formative assessment results and information, teachers require using these results effectively. In the last semester, I required submitting my research proposal, and I only had a blurry concept about it; following the formative work, my head-teacher provided me with lots of suggestions for changing my words and getting a clearer idea. It helped me substantially. Without any doubt, it required my head-teacher to be professional, since it is not easy for every educator.

The formative assessment has a strict flow to carry out. It should be strengthened step by step and not once the work is needed. There are three stages requiring consideration of the formative assessment, which include: before implementation, implementation, and post-implementation (Sadler, 1998). The first stage of the formative assessment deals with determining the stage of development of the determinants in the current stage. The following stages are based on the last stage, and, between each stage, there will be some lectures as well, where teachers require ensuring that the students get the proper knowledge for the development of their learning framework. The development phase also includes integration results of the intervention design as well as the refinement prior to the implementation.

Subsequent to the formative assessment and some learning lectures, it is expected to arrive at the summative assessment; it is the final exam for deciding whether you are going to pass or not, which is expected to make students anxious, accordingly possibly leading to unexpected results. I have known numbers of primary school students in China, who do not pass the exam. They always concentrate on their final results to fail. Together with the knowledge the teachers' teaching, the mental health has the potential to play a pivotal role in the assessment. 


\section{Areas of Development}

The policy, economy and culture are expected to impact the assessment; of course, the assessment is going to impact them back. All aspects of the assessment have social, economic and cultural aspects. Teachers require understanding not only the policy in their country, students' culture, background, and experience, aimed at ensuring that the assessment is both adequate and precise.

In the society aspect, for the achievement of results, we require evaluating learning outcomes in a positive setting (Demmert, 2005). Teachers require encouraging students to keep trying, besides not getting afraid of making mistakes so that they could understand that these wrong answers have the potential to help them find the correct answers. Students also require encouraging and understanding one another and appreciate one another's advantages and cultural details, together with actively accumulating the experience and skills. This could effectively enhance the peer evaluation (Mutch, 2012).

For instance, in China, different children in cities and rural areas receive the same assessment meanwhile getting different learning. Being honest, it is unfair to them, since they do not have sufficient financial capability for receiving a better education. Moreover, in both the cities and rural areas, the government has different policies owing to the unbalanced development. Nevertheless, when students enter the university, they must receive the same assessment for deciding their future. They always fail it absolutely, together with having some other jobs rather than learning in the university. It is termed as another function of the assessment (Harrison and Wass, 2016); it is capable of helping the society distinguish different levels of people across the globe. It is impossible for the society that everyone is able to go to the university. Or else, we do not have enough labors; the country requires a variety of talents in various industries.

With regard to the cultural aspect, in the classroom, for both students and teachers, they all require exploring their cultural values; without being good or bad, we need to know ourselves. Accordingly, in the subsequent study and evaluation, it can help one another develop one another's advantages, in addition to making up for the shortcomings of their own, finding the differences between students, and developing the space, which could be improved and promoted (Clarke, 2014). The effective assessment suggests that teachers and students require identifying the different value of one another, the hypothesis, the understanding and the teacher's evaluation of the students, besides the different responses of the students. Moreover, the effective assessment is based on a combination of factors, for instance, different cultural backgrounds, diverse values, and rich experience.

Just like the assessment, we discussed in this article, are the formative assessment and summative assessment. In the UK, they are employed in the classroom, but a different scenario prevails in China. We did not have a formative assessment before, since our teachers always wanted students to get good results at the earliest possible, so they could choose to train students to carry out numbers of practices again and again. Students are incapable of getting the feedback (Li, Su-Ting T., MD, MPH, et al, 2015); they are just trained every day. Subjected to this assessment mode, they are likely to get an extensive knowledge, but they are incapable of developing their knowledge. Accordingly, the formative assessment is a great methodology for the improvement of the critical reflection of Chinese students. Most likely, it is for the government to change values in how to promote our teenagers by means of education.

\section{References}

Berkhout, F., Hertin, J. and Jordan, A. (2002) Socio-economic futures in climate change impact assessment: using scenarios as 'learning machines'. Global Environmental Change, 12(2), pp. 83-95.

Black, P \& Wiliam, D 1998, Inside the Black Box: Raising standards through classroom assessment, School of Education, King's College, London, United Kingdom.

Black, P. (2003) Assessment for Learning: Putting It Into Practice. Open University Press.

Bredo, E. (1997) The Social Construction of Learning. In G.D. Phye (Ed.) Handbook of Academic Learning: Construction of Knowledge. San Diego, CA: Academic Press.

Bruner, J. (1996) The Culture of Education. Cambridge, MA: Harvard University Press.

Bronfenbrenner, U. (1994). Ecological models of human development. International Encyclopedia of Education, [online] 3(2), pp.37-43. [Accessed 3 May 2018]. Available at: http://www.psy.cmu.edu/ sieg ler/35bronfe brenner94.pdf 
Clark, I. (2012) Formative Assessment: Assessment Is for Self-regulated Learning. Educational Psychology Review, 24(2), pp. 205-249.

Clarke, S. (2014) Outstanding formative assessment: culture and practice. London: Hodder Education.

Dann, R. (2014) Assessment as learning: blurring the boundaries of assessment and learning for theory, policy and practice. Assessment in Education: Principles, Policy \& Practice, 21(2), pp. 149.

Demmert, W.G. (2005) The Influences of Culture on Learning and Assessment Among Native American Students. Learning Disabilities Research \& Practice, 20(1), pp. 16-23.

Gardner, J. (ED.) (2006) Assessment and Learning. London: SAGE.

German, S. (2017) Vote, discuss, revote: A formative assessment classroom technique. Science Scope, 41(2), pp. 26.

Gratton-Lavoie, C. and Stanley, D. (2009) Teaching and learning principles of microeconomics online: An empirical assessment. The Journal of Economic Education, 40(1), pp. 3-25.

Harrison, C. and Wass, V. (2016) The challenge of changing to an assessment for learning culture. Medical education, 50(7), pp. 704-706.

Harlen, W. (2005) Teachers' summative practices and assessment for learning - tensions and synergies. Curriculum Journal. 16: 2207 - 223.

Kickert, R., Stegers-Jager, K.M., Meeuwisse, M., Prinzie, P. and Arends, L.R. (2018) The role of the assessment policy in the relation between learning and performance. Medical education, 52(3), pp. 324.

Li, Su-Ting T., MD, MPH, Paterniti, D.A., PhD, Tancredi, D.J., PhD, Burke, A.E., MD, Trimm, R.F., MD, Guillot, A., MD, Guralnick, S., MD and Mahan, J.D., MD (2015) Resident Self-Assessment and Learning Goal Development: Evaluation of Resident-Reported Competence and Future Goals. Academic Pediatrics, 15(4), pp. 367-373.

MacDermott, R.J. (2013) The impact of assessment policy on learning: Replacement exams or grade dropping. The journal of economic education, 44(4), pp. 371.

Marsh, C. J. (2009) Key Concepts for Understanding Curriculum $4^{\text {th }}$ ed. London: Routledge

McLachlan, J.C. (2006) The relationship between assessment and learning. Medical education, 40(8), pp. $716-717$.

Meyers, N. and Nulty, D. (2009) How to use (five) curriculum design principles to align authentic learning environments, assessment, students' approaches to thinking, and learning outcomes. Assessment \& Evaluation in Education. 34(5), pp. 565-577.

Mutch, C. (2012) Assessment for, of and as Learning: Developing a Sustainable Assessment Culture in New Zealand Schools. Policy Futures in Education, 10(4), pp. 374-385.

Roskos, K. and Neuman, S.B. (2012) FORMATIVE ASSESSMENT: Simply, No Additives. The Reading Teacher, 65(8), pp. 534-538.

Rowntree, D. (2010). Assessing students. 1st ed. London: Routledge.

Sadler, D.R. (1998). Formative assessment: Revisiting the territory. Assessment in Education 5, no. 1: 77-85.

Vygotsky, L. (1978). Mind in Society. London: Harvard University Press.

Watts, L. and Hodgson, D. (2015) Whole Curriculum Mapping of Assessment: Cartographies of Assessment and Learning. Social Work Education, 34(6), pp. 682-699.

Wiliam, D. (2017) Assessment and learning: some reflections. Assessment in Education: Principles, Policy \& Practice, 24(3), pp. 394. 